of the apparatus, and rigidity undoubtedly is one source of its power.

In a fortnight a reapplication will probably be required. This will give a good opportunity for a careful examination of the condition of the lung. While the plasters are still on the indications of the thermometer will be most valuable. If there be an exacerbation of the symptoms, particularly of the cough, dyspnoea, or pain, if the temperature rise, or if the plasters be obviously slack, apply new ones. In an advanced case of phthisis in a girl, the girl's mother told me that she herself could tell the proper time for renewal by observing the cough become distressing at night; and, indeed, it is common for patients to ask for a reapplication. This illustrates, besides, the confidence felt in the plasters by those who have had experience of their effects. In early phthisis it is necess'ry to warn the patients not to mistake the amelioration of their symptoms for recovery; they should always be directed to come back. Possibly when they consider themselves quite well the thermometer or the stethoscope will indicate differently. These are the cases in which, by reapplications, repeated reapplications if necessary, we may hope for the most brilliant results.

In the paper already referred to I have related a few cases, selected with the aim of illustrating the effects of this line of treatment in different stages of the disease. We obtain immediate and marked diminution of the cough, cessation of pain, relief of dyspnca, and reduction of temperature; and the patient usually expresses at once a feeling of great comfort. In short, I am so satisfied with the results of the numerous cases in which I have tried this method that I give it the first place among all the remedies for phthisis.

Papers on the subject. - Berkart on "Rest," \&c., THE LINCET, Oct. 18th, 1073; a letter from myself in the following number of the same journal; my paper in the Dublin Medical Journal, Novemher, 1873; Dobell on the "Importance and Dangers of Rest in Pulmonary Consumption," in the British Medical Journal, Nov. 22nd, 1873.

Belfast.

\section{SUBPERIOSTEAL EXCISION OF HUMERUS.}

\section{By J. A. DONOVAN, M.D.}

ON the morning of December 15th, 1872, while engaged in practice at Lewiston, Maine, U.S.A., I was hastily called to attend Daniel $\mathrm{M}$ - aged fifteen, who was said to be bleeding profusely from the nose. On reaching the boy's place of residence, it was ascertained that the hæmorrhage occurred first on the previous day, but ceased spontaneously. The second attack, being more severe, was treated by the application of solution of subsulphate of iron to the nasal mucous membranes and a little ice bag across the brows. The patient was fairly nourished and of medium development. The parents were healthy, as were a brother and sister, who comprised the family. A cousin died of phthisis, and other cousins manifested strumous tendencies. The patient's surroundings and home comforts were very satisfactory. He was now evidently very ill. The temperature, notwithstanding the loss of blood in considerable quantity, was elevated. The pulse was 130, and small in volume.

No appearance of local disease, to explain his constitutional disturbance, could be found, except a small patch of redness a little below and external to the coracoid process of the right scapula, corresponding with the neck of the humerus. There was a little swelling and heat at the inflamed part, and it hurt him to move the arm. The treatment was a suitable confinement of the arm to the body to ensure rest; and the extract of opium, made fluid with water, was freely painted over tbe inflamed part. He was given quinia with morphia sufficient to procure necessary sleep and freedom from pain.

Next day the patient appeared better, but the inflamed surface bad increased to double its extent of the day before; it was exceedingly tender to the touch, and was plainly an acute periostitis. His temperature appeared lower; pulse 118 ; appetite improved; and no return of the epistaxis. The parents, believing the case to be a mild attack of acute rheumatism, which was prevalent at that time in their locality, desired me to discontinue my attendance, and promised tu report if the patient did not progress farourably.
Four days later they did report that their boy was recovering satisfactorily.

On Dec. 25th, ten days after the first visit, I met with the patient's father, who informed me that the boy's arm was much swollen, but not painful ; and that he was feeble. He desired me to see the patient if deemed necessary. The arm was then found to be very tense and immensely swollen. It fluctuated freely from the top of the shoulder nearly to the elbow. The hand and forearm were very œdematous. The patient had emaciated rapidly; had had chills and perspirations; and by his appearance gave ample evidence of severe suffering, though he would not admit it. An incision through the soft parts, nearly corresponding with the patch of redness first observed, gave exit to a large quantity of ill-formed pus, containing numerous little clots of dark blood. The finger then came directly in contact with bare and finely-roughened bone. It could be passed around the neek of the humerus, upwards into the capsule, and downwards its length. The periosteum was detached extensively
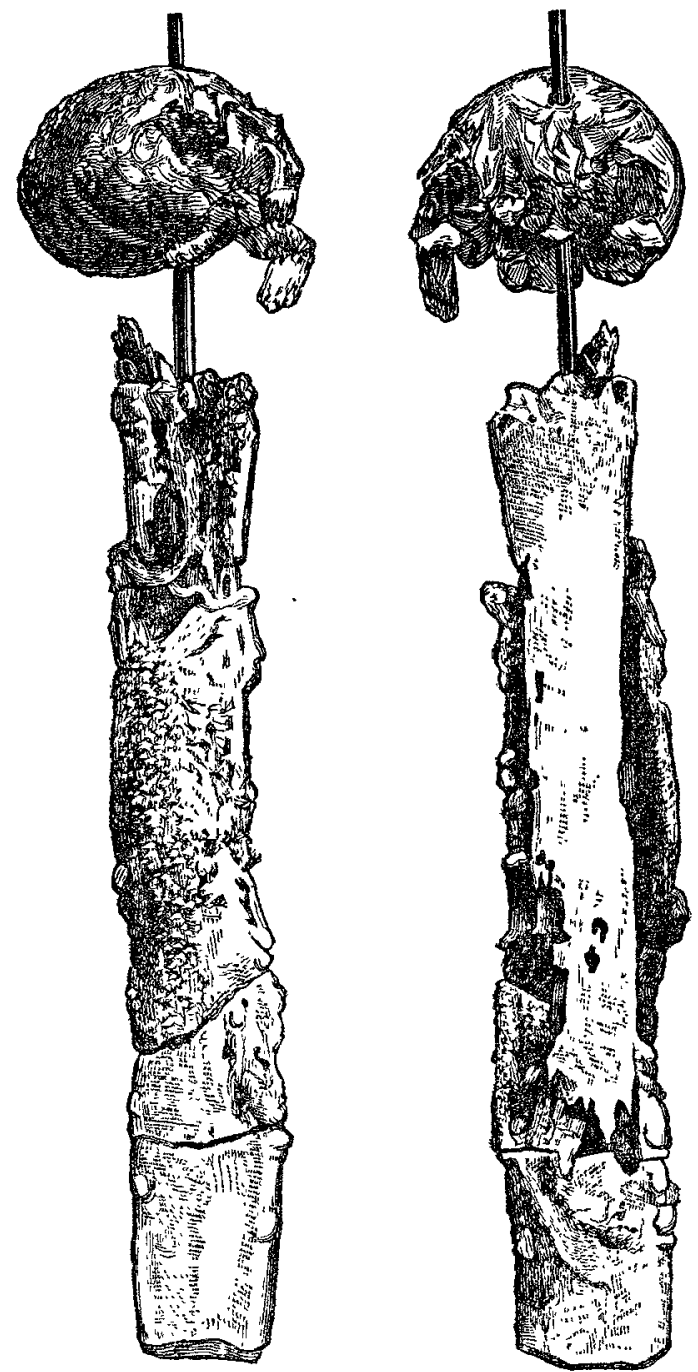

The above figures, half the original size, represent opposite surfaces of the bone, as well as different phases of the morbid proces The head and secterts morbid procss. The head and sere kept in relation by a wire passing through them. The interspace seen between the head and shaft shows as nearly ration.

from the outer and posterior surfaces of the bone. Three days later the patient was etherised, and another opening made between the condyles at the bottom of the carity. A long probe passed readily from the upper through the lower incision, and the pus drained completely away. He was then relieved of most of his pain.

The patient did well until Jan. 20th, 1873, when his arm began to be painful again, but not from confined pus. An intense erythematous redness soon diffused itself over the arm, accompanied by considerable swelling. The whole humerus seemed to be acting as a foreign body. Severe constitutional disturbance again appeared, having as principal features chills, perspirations, and diarrbca.

On Jan. 23rd it was decided to operate, and to perform the kind of operation that seemed most advisable after exposing the humerus. The incisions made for the escape of 
pus were in the proper lines for extirpating the bone. The upper one was carried upwards the required distance to remove the head, and downwards below the central point of the shaft, curving forwards to avoid the musculo-spiral nerve. The periosteum, where attached, was easily separated, and the capsule was much diseased. While attempting to turn out the head of the bone, its neck broke away, being extensively diseased, though preserving its form perfectly. The shaft, freed from its membrane, was turned out and divided as low as possible. The posterior puncture was enlarged to the necessary extent. The lower portion of the humerus was treated as in the previous case, and divided just above the condyles. The glenoid cavity was not diseased. The flaccid arm was then placed upon a comfortably padded angular splint; while the patient, though alarmingly prostrated, rallied well and made a good and uninterrupted recovery. The reproduction of bone was rapid and very perfect.

By March 26th, 1873, the use of the splint was discontinued during the day, but worn at night a little longer. The new shaft was firm, and apparently of equal diameter throughout. Shortening from one to two inches. There was perfect motion at the elbow-joint, and at the shoulder in all directions except abduction, six months after excision. At that time the arm was very useful. The patient could easily raise his hand to his mouth, carry with it a pail of water, and make it generally useful. The scapulo-humeral muscles atrophied greatly, but the arm retained a very respectable size, and is constantly improving. No paralysis of the hand or forearm followed. The bone at the lower point of section was somewhat vascular, and looked fairly healthy; but the periosteum was thickened and easily detached, like the bark from a soft twig. The medullary substance was greenish in colour and wanting in vascularity. That portion of periosteum corresponding with the necrosed surface of the humerus was covered by a thin film of bony formation, which apparently perished when the humerus took on the carious form of disease.

It would appear that in this case the retention of pus not only caused much suffering, but greatly complicated the mischief primarily developed as a circumscribed acute periostitis; and although its history cannot fail to suggest the existence of strumous or other morbid elements, it is more than probable that if an early exit had been given to the pent-up fluid the humerus might not have perished in its entirety, but have cast off a sequestrum, as in ordinary cases of necrosis.

Palace-road, Lambeth.

\section{GENERAL COUNCIL OF MEDICAL EDUCATION \& REGISTRATION.}

\section{Session 1874.}

Thursdax, July 9th.

Dr. PAGet, President, in the chair.

AT the conclusion of the President's address (which was reported at length in last week's LANCET) the following Report was presented from the Executive Committee as to the new premises:-

REPORT OF EXECUTIVE COMMITTEE AS TO THE NEW OFHICES OF THE COUNCIL.

"In pursuance of the resolution of the General Medical Council of March 5th, 1872, the Executive Committee have been in communication with the Government, as the Council are aware, for many months. After protracted negotiations, they have at last succeeded in obtaining the premises in which the Council are summoned to meet; well known as formerly the Royal College of Chemistry. The terms on which the house has been granted have been made known to members of the Council by the Minutes of the Executive Committee from February 23rd to March 27th, 1874. They are, shortly stated, a lease of $31 \frac{1}{4}$ years, at a yearly rent of $£ 300$, the Government undertaking to expend $\$ 1500$ in adapting the building to the wants of the Council, and reserving a right of terminating the lease at the end of seven, fourteen, or twenty-one years. It is estimated that the total annual expenses of the house, including tbe care of it, the rates, and all other charges, will not be less than $\$ 460$. This should be borne in due proportions by the General Medical Council and the English Branch Council. The latter Council resolved, April 2nd, 1874, that they will be prepared to contribute for their accommodation in the same proportion as they have hitherto done in Soho-square. This offer of the English Branch Council is very advantageous to the General Council, and the Executive Committee therefore recommend the Council to accept it. If this arrangement be adopted, the annual expense chargeable to the General Council may be estimated at one-third of $\$ 460$ i. e., $\$ 1536 s .8 d$., which will have to be defrayed out of the percentage rate, and will therefore fall on the several Branch Councils in proportions which will vary a little from jear to year. Taking the percentage rate as it has been on the average of the last three years, the incidence of the expense of the house on the Branch Councils was be estimated as follows:-

The English Branch will pay-

Two-thirds of 2460 . . . . . . $\$ 306134$

Rateable proportion of $21536 s .8 d . \quad 106 \quad 8 \quad 5$

$-2413 \quad 1 \quad 9$

The Irish Branch will pay $\begin{array}{lll}25 & 2 & 3\end{array}$

$£ 460 \quad 0 \quad 0$

A considerable sum must also be expended in paying for the requisite furniture and fittings. The amount cannot be exactly estimated at present, but it is thought that it will not much exceed $£ 500$. The Executive Committee regret that, notwithstanding the strenuous exertions of the Office of Works, the building is still in a somewhat unfinished state."

On the motion of Dr. Storrar, seconded by Dr. PxLe, the Council expressed its approval of the arrangement recommended by the Executive Committee for the apportionment of payment by the Branch Councils of rent, taxes, and expenses of offices, \&c.

The following opinion of counsel respecting diplomas in midwifery issued by the Queen's University in Ireland was read:- "We are clearly of opinion that the Medical Council cannot register the diplomas granted by the Queen's University in Ireland." (Signed) G. Jessed, Charles Bower.

\section{REPORTS OF VISITATIONS OF EXAMINATIONS.}

On a motion by Dr. ANDREw Wood, "That the reports of the visitors of the examinations be received and entered on the Minutes,"

Dr. STORRar asked if it was desirable to make public all the details contained in those reports, some of which might be calculated to give pain to some of the bodies concerned, or certain members of those bodies. The duty of visitation was one of the most important functions which the Council could exercise; but much of its value would depend upon the spirit in which it was carried out. And if it should occur to any gentleman connected with the bodies visited that there had been manifested a spirit of querulousness, or a disposition to find fault, the Council would utterly fail in achieving the advantages anticipated from the visitations. The duty should be exercised in a friendly way on the part of the Council, and accepted by the bodies in the same spirit. Instead of appointing a committee to make a précis of the reports, he thought the better course would be to send the documents confidentially, and in the spirit of cor operation, to the bodies inspected, asking their particulaattention to them. The result would be that, where faults had existed, remedies would be provided. If, from mere usage, bodies of considerable standing had fallen into routine and laxity of arrangement, an opportunity would be afforded of introducing improved methods. A few years ago there was a visitation of the University of London. The visitors approved highly of the general examinations, but thought that the written questions should be more numerous. The Senate, on inquiry, found that there was room for improvement in that respect, and gave directions that the written questions should in future be more numerous.

Dr. PARKes said he did not know how the reports (which had been made with great care) could be brought under the notice of the Council unless they were placed on the Minutes in the usual way. 